\title{
Hydrophobic Coatings from Photochemically Prepared Hydrophilic Polymethacrylates via Electrospraying
}

\author{
Tuğba Isık, ${ }^{1}$ Mustafa M. Demir, ${ }^{1}$ Cansu Aydogan, ${ }^{2}$ Mustafa Ciftci, ${ }^{2}$ Yusuf Yagci $^{2}$ \\ ${ }^{1}$ Department of Materials Science and Engineering, Izmir Institute of Technology, Urla, İzmir, 35430, Turkey \\ ${ }^{2}$ Department of Chemistry, Faculty of Science and Letters, Istanbul Technical University, Maslak, İstanbul, 34469, Turkey \\ Correspondence to: M. M. Demir (E-mail: mdemir@iyte.edu.tr) or Y. Yagci (E-mail: yusuf@itu.edu.tr)
}

Received 28 November 2016; accepted 20 December 2016; published online 3 February 2017

DOI: $10.1002 /$ pola.28501

ABSTRACT: Linear poly(hydroxyethyl methacrylate-co-methyl methacrylate) P(HEMA-co-MMA) and poly(dimehylaminoethyl methacrylate-co-methyl methacrylate) P(DMAEMA-co-MMA) and their corresponding hyperbranched copolymers were synthesized by conventional photoinitiated free radical polymerization and self-condensing vinyl polymerization (SCVP) using Type I and Type I/ photoinitiators, respectively. Then, the polymers were processed by electrospraying in $N, N$-dimethylformamide. The surface of the resulting electrospray coatings was examined by SEM, XPS, and WCA then compared with those prepared by drop casting.
Regardless of the structural nature of the polymers, electrospraying allows the preparation of rough surface that shows more hydrophobic behavior. Electrospray coatings with linear and hyperbranched copolymers exhibited WCA as $\sim 150^{\circ}$ and $\sim 130^{\circ}$, respectively, indicating that branching reduces the WCA. (c) 2017 Wiley Periodicals, Inc. J. Polym. Sci., Part A: Polym. Chem. 2017, $55,1338-1344$

KEYWORDS: electrospinning; electrospray; hyperbranched copolymers; photopolymerization; superhydrophobicity
INTRODUCTION Water repellency is a crucial feature for the potential applications such as anti-contamination and selfcleaning technologies. ${ }^{1-4}$ Nature designs unique and unusual Lotus leaves, which shows superhydrophobicity and self-cleaning feature due to having hierarchical micro- and nano-structure on leaf surface that minimizes the droplet's adhesion. The wetting capability of a solid surface can be utilized by measuring the contact angle of the liquid on that surface and it is widely known that superhydrophobic surfaces show substantially high water contact angle (WCA, close to or higher than $150^{\circ}$ ). ${ }^{5,6}$ Tailoring the chemical composition and the surface roughness ${ }^{7}$ allow to control the wettability of surfaces. So far, many methods have been developed to fabricate rough surfaces such as etching, ${ }^{8}$ deposition, ${ }^{9}$ sol-gel, ${ }^{10}$ electrospraying, ${ }^{11}$ and lithography. ${ }^{12}$ Electrospraying has been recognized as a powerful approach to obtain high surface roughness. It is a well-established process based on the application of high electrical voltage to a polymer solution. The process relies on the flowing out of a liquid from the capillary nozzle and then forming a fine jet following by atomization of liquid into fine droplets. ${ }^{13}$ A grounded conductive substrate is employed to collect the coating material. The viscosity of the sample solution (both concentration and molecular weight) is the dominant parameter for the morphology of the resulting coating. Low solution viscosity yields electrospraying that causes the formation of spheres of different size on the collector. On the other hand, at high viscosity (high concentration and/or high molecular weight) the process shifts to electrospinning regime. The continuous micron/submicrometer fibers are obtained due to severe entanglement of polymer chains. ${ }^{14}$

It has been apparently showed that hydrophobic behavior of the electrospraying/electrospinning surface results from the high surface roughness such that changing the surface topography can minimize the interfacial energy between solid and liquid. Notably, the presence of fluorine atoms or fluorine containing groups is considered to be prerequisite that renders the hydrophobicity of the surfaces by reducing the surface tension. For instance, Zheng et al. produced polymer surfaces with high WCA by electrospraying of polystyrene. ${ }^{15}$ Polyvinyl butyral nanofibrous mats exhibit hydrophobic and superoleophilic properties and high separation efficiency for oil-water mixtures. ${ }^{16}$ Guo et al. also synthesized poly (methyl methacrylate)- $b$-poly (dodecafluoroheptyl methacrylate) diblock copolymer and established superhydrophobic surfaces with lotus effect by electrospraying of this copolymer. ${ }^{17}$

Hyperbranched polymers represent inherent characteristics compared to their linear analogs due to the peculiar properties such as higher solubility, reduced solution viscosity ${ }^{18,19}$ and increased level of terminal functionality. ${ }^{20,21}$ In recent years, many approaches have been developed for the synthesis

Additional Supporting Information may be found in the online version of this article.

(c) 2017 Wiley Periodicals, Inc. 
of such complex architectures. ${ }^{22-24}$ Among them, selfcondensing vinyl polymerization (SCVP) is the most widely used technique due to the operational simplicity and synthetic versatility to form highly branched structures with desired functional groups. ${ }^{25}$ It has also been modified to a wide variety of controlled polymerization systems via inimer structure variations. $^{26-29}$ In the recent reports from the authors' laboratory, novel photochemical methods have been introduced for the preparation of hyperbranched polymers. Depending on the structure of the inimer, either photo-induced bromine abstraction by $\mathrm{Mn}_{2}(\mathrm{CO})_{10}{ }^{30}$ or the reaction of photochemically generated radical with double and triple bonds at different rates, were successfully employed. ${ }^{31}$ In this connection, it should be pointed out that the organomanganese compound used in the process can also be applied for the fabrication of various macromolecular structures through a similar halide abstraction process. ${ }^{32-36}$

In this work, we employed poly(methyl methacrylate) (PMMA)-based copolymers consisting of two types of comonomer segments, hydroxyethyl methacrylate (HEMA) and dimethylamino ethyl methacrylate (DMAEMA) $<10 \mathrm{~mol} \%$. The effect of chain topology (linear and hyperbranched) for different levels of branching and chemistry of comonomers on water contact angle of the electrosprayed coating is examined. We have shown that chain architecture and structural differences have strong influence on the surface chemistry, morphology, and therefore, wettability.

Two distinct theoretical models, Wenzel $^{37}$ and Cassie-Baxter, ${ }^{38}$ have been used to explain the influence of surface energy and roughness on the wetting behavior of a surface. Their models are described by the following equations,

$$
\begin{gathered}
\cos \theta_{W}=r \cos \theta_{0} \\
\cos \theta_{C B}=f_{1} \cos \theta_{0}-f_{2}
\end{gathered}
$$

where $\theta_{0}$ is the contact angle on a smooth surface, $r$ is the roughness factor, $f_{1}$ and $f_{2}$ are the fractions of solid surface and air in contact with liquid, and $\theta_{W}$ and $\theta_{C B}$ are apparent contact angles on a rough surface for Wenzel and Cassie-Baxter, respectively. Wenzel model claims that the rough surface has higher surface area than a smooth surface and water droplet wets a smaller area that results in a higher contact angle. However, this model is valid only for the hydrophobic materials which have $\theta_{0}>90^{\circ}$ on a smooth surface. For the surfaces having $\theta_{0}<90$, surface roughness enhances the hydrophilicity due to the high hysteresis. In the Cassie-Baxter model, the droplet sits on the composite surface, which consists of trapped air and solid. These composite surfaces would have higher contact angles based on the air-liquid interface and small hysteresis. ${ }^{39}$ This model was approved for the analysis of chemically heterogeneous surfaces and rough surfaces with air pockets. ${ }^{40}$

\section{EXPERIMENTAL}

\section{Materials}

Methyl methacrylate (MMA, Aldrich, 99\%) and hydroxyethyl methacrylate (HEMA, 99\%, Aldrich) were passed through a column of alumina to remove inhibitor initially present in the monomers. Dimethylamino ethyl methacrylate (DMAEMA, 98\%, Aldrich) was distilled prior to polymerization. Camphorquinone (CQ 97\%, Aldrich), bisacylphosphine oxide (BAPO, Ciba, Specialty Chemicals), toluene (98\%, Aldrich), $N, N$-dimethylformamide (DMF, Reagent Plus $\geq 99 \%$, Sigma-Aldrich), and methanol (MeOH; 99.9\%, Merck) were used as received.

\section{Synthesis of Hyperbranched Polymers}

The procedure of the copolymer synthesis was given in detail elsewhere. ${ }^{41}$ A typical photopolymerization procedure was applied for the synthesis of hyperbranched polymers. Briefly, MMA (1 mL, $9.38 \mathrm{mmol}$ ), inimer (either HEMA or DMAEMA, 5\%, 7.5\% mol), photoinitiator (CQ 1\% mol), and toluene $(1 \mathrm{~mL})$ were put in a Pyrex tube and filled with dry nitrogen prior to irradiation by a photoreactor emitting light nominally at $400-500 \mathrm{~nm}$ at room temperature. At the end of irradiation, polymer was precipitated in excess methanol and dried under reduced pressure.

\section{Synthesis of Linear Polymers}

MMA (2 mL, $18.7 \mathrm{mmol}$ ), inimer (either HEMA or DMAEMA, $7.5 \% \mathrm{~mol}$ ), photoinitiator (BAPO, 0.5\% mol), and toluene (2 mL) were put in a Pyrex tube and filled with dry nitrogen prior to irradiation by a Ker-Vis blue photoreactor equipped with 6 lamps (Philips TL-D $18 \mathrm{~W}$ ) emitting light nominally at 400-500 $\mathrm{nm}$ at room temperature. At the end of irradiation, polymer was precipitated in excess methanol. The obtained polymers were dried under vacuum for $24 \mathrm{~h}$. Conversions for all samples were determined gravimetrically.

The structure of polymers was evidenced by Nuclear Magnetic Resonance (NMR, Agilent NMR System VNMRS 500 spectrometer) and Fourier Transform Infrared Spectroscopy (FT-IR, Perkin-Elmer FT-IR Spectrum One B spectrometer) at room temperature. In order to determine branching frequency, both apparent and absolute molecular weights were measured from a Viscotek GPCmax Autosampler system consisting of a pump module (GPCmax, Viscotek Corp., Houston, TX), a combined light scattering (Model 270 Dual Detector, Viscotek Corp.), and a refractive index (RI) detector (VE 3580, Viscotek Corp.). The ratio between $M_{\mathrm{n}, \mathrm{RI}}$ and $M_{\mathrm{n}, \mathrm{DLS}}\left(R_{\mathrm{M}}=M_{\mathrm{n}, \mathrm{RI}} / M_{\mathrm{n}, \mathrm{DLS}}\right)$ gives qualitative information about the branching density of the polymers since branched structures are more compact than linear polymers for a given molecular weight. ${ }^{42}$

\section{Fabrication of Coatings}

The above-obtained copolymers were dissolved separately in $1 \mathrm{~mL}$ of DMF with $15 \mathrm{w} / \mathrm{v} \%$ concentration and stirred for $12 \mathrm{~h}$ until homogeneous solutions were achieved. Then, each solution were transferred into the $2 \mathrm{~mL}$ plastic syringe with stainless steel needle (18 gauges) and the needle was connected horizontally to a high voltage supply under $12 \mathrm{kV}$. (Gamma High Voltage Research Ormond Beach, FL). Using a microinfusion pump, (New Era NE300 Infusion Pump, Farmingdale, NY, USA) the flow rate was fixed as $2 \mathrm{~mL} \mathrm{~h}^{-1}$ and tip to collector distance was set as $15 \mathrm{~cm}$. (The potential difference was $0.8 \mathrm{kV} \mathrm{cm}^{-1}$.) Electrospray beads were obtained on the grounded aluminum foil collector. The morphology of 
(A)

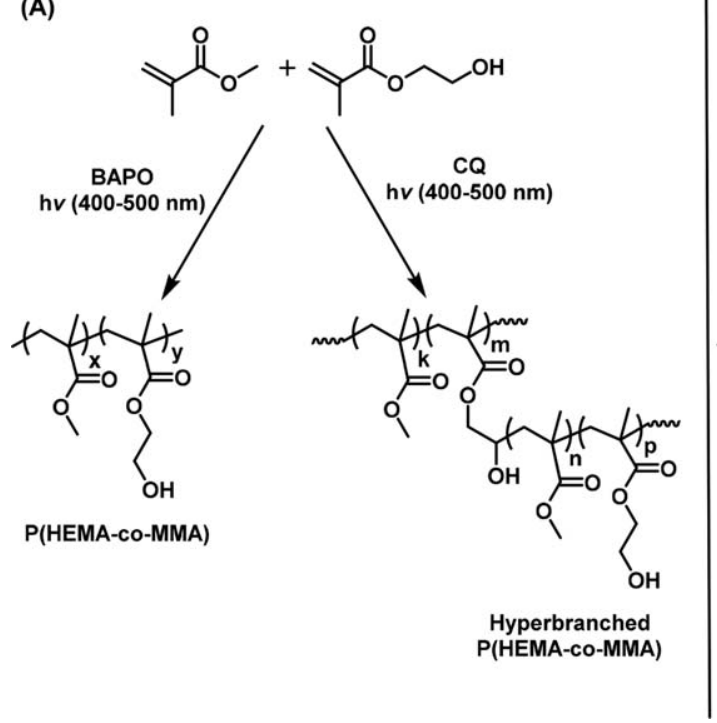

(B)

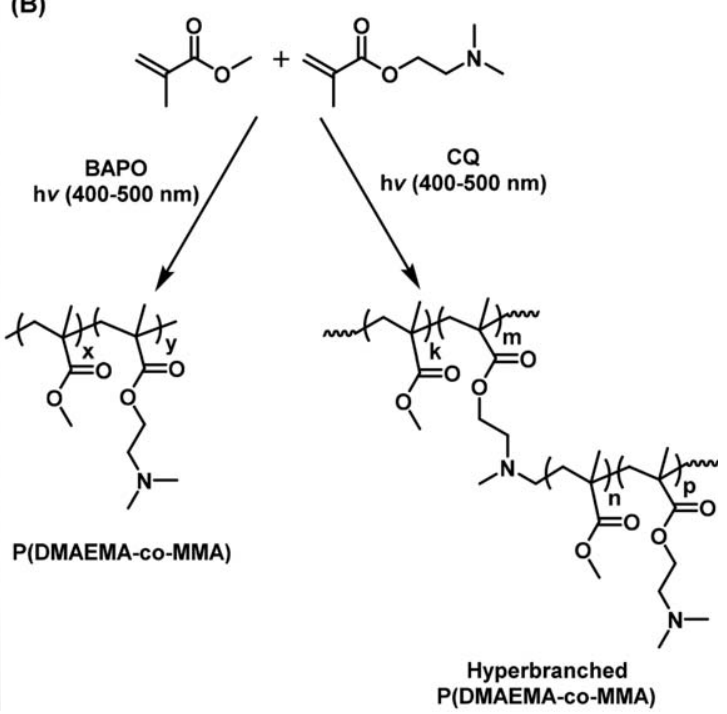

SCHEME 1 Synthesis of linear P(HEMA-co-MMA)/hyperbranched analog (A) and P(DMAEMA-co MMA)/hyperbranched analog (B).

samples was examined using Scanning Electron Microscope (SEM, FEI Quanta250 FEG, OR). The surface chemical compositions of samples were determined by X-Ray Photoelectron Spectrometer (XPS, Thermo Scientific K-Alpha Surface Analysis, MA). Contact angle measurements were achieved with Contact Angle Meter. (Attension Lite, Biolin Scientific, Stockholm, Sweden) The average size of the beads were estimated by statistically from SEM micrographs using Image software. ${ }^{43}$

For the drop casting, the glass slides were covered with aluminum foil to attain flat surfaces. Then, synthesized copolymers were dissolved in $200 \mu \mathrm{L}$ DMF with $3 \mathrm{w} / \mathrm{v} \%$ concentration and casted on flat aluminum foils as check samples. The coatings were air-dried for $24 \mathrm{~h}$ prior to characterizations.

\section{RESULTS AND DISCUSSION}

In the applied photochemical synthetic strategy, the type of photoinitiator plays a crucial role on the structure of the polymers formed. Type I photoinitiators such as bisacyl phosphine oxide (BAPO) yield linear polymers while Type II photoinitiatiors such as camphourquinone (CQ) resulted in the formation of hyperbranched polymers (Scheme 1). For the latter case, methylmethacrylate (MMA) was photochemically copolymerized with comonomer (either HEMA or DMAEMA) possessing both polymerizing and initiating sites in the structure in the presence of CQ. Upon irradiation, the excited photoinitiator abstracts hydrogen from the comonomer leading to the formation of initiating radicals. Since comonomer molecules combine features of an initiator and a monomer, they are named as "inimer." As a consequence of the process, hydrogen donating sites of the inimer (either hydroxyl or amine) remained unchanged and thus the resulting hyperbranched polymers contained a fraction of functional groups in their structures.

As can be seen from Table 1, molecular weight of the linear copolymers increased with the irradiation time while both molecular weight and branching density of the hyperbranched copolymers increased with the inimer content in the feed. The relative inimer concentration was deliberately kept low $(7.5 \mathrm{~mol} \%)$ to avoid solubility problems. The higher inimer concentrations and prolonged irradiation times results in higher branching, but partially insoluble materials.

The structure of the synthesized polymers was confirmed by spectral analysis. The ${ }^{1} \mathrm{H}$-NMR spectra of the hyperbranched polymers exhibit characteristic MMA repeating unit protons as well as the characteristic bands of the inimer segments (Fig. S1a, Supporting Information).

The composition of the hyperbranched polymers is estimated by ${ }^{1} \mathrm{H}$ NMR analysis by the comparison of the protons signals of methyl group of PMMA with the methylene protons of the inimer segment next to the ester functionality. It should be pointed out that the content of the inimers in the final structure is higher than that in the feed in all cases. This behavior might be attributed to the difference of the propagation rate constants $k_{\mathrm{MMA}}=6.42 \times 10^{2} \mathrm{~L} \mathrm{~mol}^{-1} \mathrm{~s}^{-1}, k_{\mathrm{HEMA}}=2.56 \times 10^{3}$ $\left.\mathrm{L} \mathrm{mol}^{-1} \mathrm{~s}^{-1}, k_{\text {DMAEMA }}=2.64 \times 10^{6} \mathrm{~L} \mathrm{~mol}^{-1} \mathrm{~s}^{-1}\right) .44,45$

The structure of the polymers was also studied by FT-IR analyses (Fig. S1b, Supporting Information). The characteristic ester stretching bands centered at $1730 \mathrm{~cm}^{-1}$ were observed and the broad signal originating from hydroxyl group corresponds to HEMA moieties $\left(3500 \mathrm{~cm}^{-1}\right)$.

The polymers with different branching densities and molecular weights were dissolved in DMF with a concentration of $15 \mathrm{w} / \mathrm{v} \%$ and subjected to electrospraying at $0.8 \mathrm{kV} \mathrm{cm}^{-1}$. Usually, beads are formed when the polymer solution is fairly diluted due the insufficient viscosity. ${ }^{15}$ The SEM micrographs of the drop casting and electrospray coating surfaces of the linear and hyperbranched P(HEMA-co-MMA) copolymers are given in Figure 1. The surfaces prepared by drop casting of Lin-PH1 and Hyp-PH1 copolymers appear flat and 
TABLE 1 Photoinduced Synthesis and Molecular Weight Characteristics of Linear and Branched PMMA Copolymers

\begin{tabular}{|c|c|c|c|c|c|c|c|c|c|}
\hline Sample & Comonomer & $\begin{array}{l}\text { Irradiation } \\
\text { Time } \\
(\min )\end{array}$ & $\begin{array}{l}\text { Inimer cont. } \\
\text { in feed } \\
{[\mathrm{mol} \%]}\end{array}$ & $\begin{array}{l}\text { Conv. } \\
{[\%]^{a}}\end{array}$ & $\begin{array}{l}\text { Inimer cont.in } \\
\text { the polymer } \\
{[\mathrm{mol} \%]^{\mathrm{b}}}\end{array}$ & $\begin{array}{l}M_{\mathrm{n}, \mathrm{GPC}-\mathrm{RI}} \\
{\left[\mathrm{g} \mathrm{mol}^{-1}\right]^{\mathrm{C}}}\end{array}$ & $\begin{array}{l}M_{\mathrm{n}, \mathrm{GPC}, \mathrm{LS}} \\
{\left[\mathrm{g} \mathrm{mol}^{-1}\right]^{\mathrm{d}}}\end{array}$ & $R_{\mathrm{M}}^{\mathrm{e}}$ & Structure \\
\hline Lin- $\mathrm{PH} 1^{f}$ & HEMA & 30 & 7.5 & 16 & 10.5 & 10500 & 11600 & 0.90 & Linear \\
\hline Lin-PH2 ${ }^{f}$ & HEMA & 60 & 7.5 & 27 & 10.7 & 25000 & 29000 & 0.86 & Linear \\
\hline Нур-PH ${ }^{\mathrm{g}}$ & HEMA & 150 & 5 & 39 & 10.2 & 30800 & 65700 & 0.47 & Hyperbranched \\
\hline Hyp-PH $2^{g}$ & HEMA & 150 & 7.5 & 47 & 12.9 & 31000 & 79600 & 0.39 & Hyperbranched \\
\hline Lin-PD1 ${ }^{f}$ & DMAEMA & 30 & 7.5 & 18 & 12.6 & 7700 & 9000 & 0.85 & Linear \\
\hline $\operatorname{Lin}-P D^{f}$ & DMAEMA & 60 & 7.5 & 38 & 12.8 & 14000 & 15.600 & 0.89 & Linear \\
\hline Hyp-PD1 ${ }^{g}$ & DMAEMA & 150 & 5 & 46 & 11.4 & 14200 & 73200 & 0.19 & Hyperbranched \\
\hline Hyp-PD2 ${ }^{g}$ & DMAEMA & 150 & 7.5 & 59 & 14.4 & 12600 & 90100 & 0.34 & Hyperbranched \\
\hline \multicolumn{5}{|c|}{$\begin{array}{l}\text { a Determined gravimetrically. } \\
{ }^{b} \text { Calculated from the }{ }^{1} \mathrm{H} \text { NMR. } \\
{ }^{\mathrm{c}} \text { With refractive index detector. } \\
{ }^{\mathrm{d}} \text { With light scattering detector. }\end{array}$} & \multicolumn{5}{|c|}{$\begin{array}{l}{ }^{f} \text { Photopolymerization at room temperature in the presence of BAPO } \\
(0.5 \mathrm{~mol} \%) \text {. } \\
\mathrm{g} \text { Photopolymerization at room temperature in the presence of } \mathrm{CO} \\
(1 \mathrm{~mol} \%) \text {. }\end{array}$} \\
\hline
\end{tabular}

show hydrophilic behavior with a water contact angle (WCA) of $87^{\circ}$ and $72^{\circ}$, respectively. (Fig. 1a,b) The electrospraying process changes the morphology of both Lin-PH1 and HypPH1 surfaces from flat to rough by disintegration of polymer solution into porous spherical beads. This rough surface

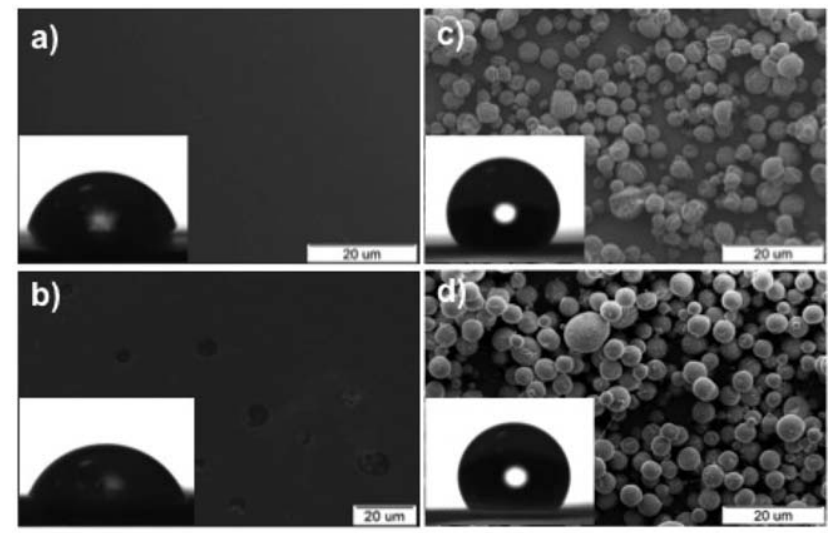

e)

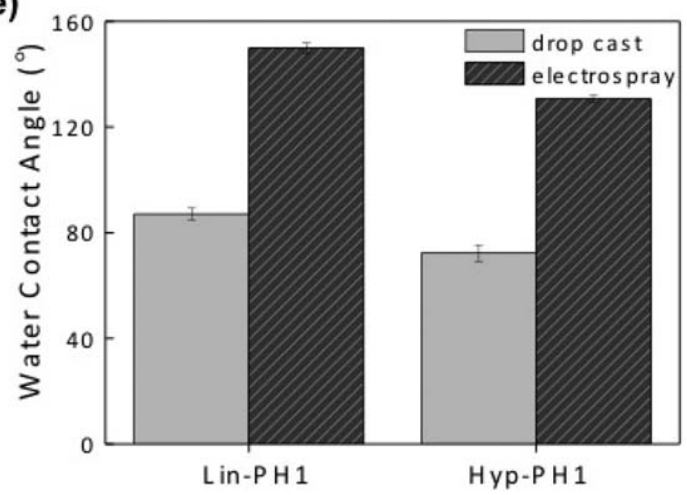

FIGURE 1 SEM micrographs of copolymers (a) Lin-PH1 drop cast, (b) Hyp-PH1 drop cast, (c) Lin-PH1 electrospray, and (d) Hyp-PH1 electrospray samples. Insets show profiles of water droplets with their water contact angles. (e) Water contact angle comparison of Lin-PH1 and Hyp-PH1 samples. increases the WCA up to $150^{\circ}$ and $131^{\circ}$, respectively, meaning that the surface shows almost superhydrophobic behavior (Fig. 1c,d). The size of beads is heterogeneous in diameter (Fig. S2, Supporting Information). Therefore, the electrospray coating shows broader distribution in roughness amplitude and develops a macroscopic level of roughness. For the heterogeneous patterned surface and the presence of cavities, more air is trapped underneath the film to support water droplets, and therefore, corresponds to a more hydrophobic surface as compared to film casting surface.

It is well known that the water contact angle of air is assumed $180^{\circ}$ and trapped air has a significant importance on the hydrophobicity. Electrospraying improves the surface hydrophobicity by increasing the surface roughness and the resulting polymer microspheres decrease the contact area between solid and water while the contact area between the air and water is enhanced. ${ }^{46}$ The insets in Figure 1 shows the optical photographs of water droplets on the surfaces prepared by drop casting and electrospray coating. The behavior of this type non-ideal surface is generally explained in terms of either Wenzel model or Cassie-Baxter model. Basically, Cassie-Baxter model postulates that droplets hang on the rough surfaces and allow air trapping between the surface and the droplet. ${ }^{47}$ When the WCA of flat surfaces (namely drop casting ones) and rough electrospray coatings were compared, our proposed electrospray coatings have much greater value than the drop casting ones (up to $60^{\circ}$ ) due to the deposition of irregular microspheres and trapped air between them. This outcome demonstrates that electrospray coatings better fits to Cassie-Baxter model.

A similar comparison was applied between film casting and electrospray coating of Lin-PD2 and Hyp-PD1 copolymers. Contrasting to Lin-PH1 and Hyp-PH1, these copolymers show already hydrophobic behavior when they were drop casted. The electrospray process increases the WCA of hydrophobic surfaces from $92^{\circ}$ to $116^{\circ}$ and from $112^{\circ}$ to $135^{\circ}$ 

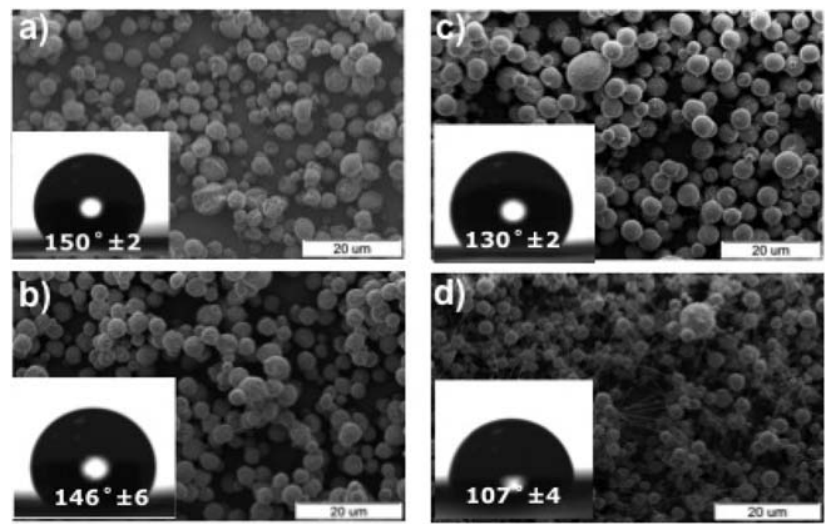

FIGURE 2 SEM micrographs and WCA profiles of (a) Lin-PH1, (b) Lin-PH2, (c) Hyp-PH1, and (d) Hyp-PH2 copolymers.

for both linear and hyperbranched copolymers, respectively (Fig. S3, Supporting Information). While Lin-PD2 drop cast film has a flat surface, Hyp-PD1 film consists of bubble-like morphology that results in higher WCA for hyperbranched sample.

Figure 2 demonstrates SEM micrographs of the electrospray coatings from linear and hyperbranched copolymers. The coatings prepared from hyperbranched samples show lower WCA than those prepared from the linear chains. WCA of linear samples are $146^{\circ}$ and $150^{\circ}$, whereas the one of hyperbranched samples are $130^{\circ}$ and $107^{\circ}$. The size of beads are $3.0 \pm 0.3 \mu \mathrm{m}$ and $3.3 \pm 0.6 \mu \mathrm{m}$ for Lin-PH1 and Lin-PH2, and $3.6 \pm 0.7 \mu \mathrm{m}$ and $2.4 \pm 0.4 \mu \mathrm{m}$ for Hyp-PH1 and Hyp-PH2 samples, respectively (Fig. S2, Supporting Information). Note that in addition to beady structure, fiber formation is observed in some regions of Figure $2 \mathrm{~d}$.

The surface morphology of the all electrosprayed samples looks similar at first glance. So that, the surface composition of the samples was examined by XPS to get insight about the surface chemistry of the linear and hyperbranched surfaces along with drop casting films. The survey XPS spectra of $\mathrm{C}(1 \mathrm{~s})$ and $\mathrm{O}(1 \mathrm{~s})$ regions for the drop casting and electrospray coating of P(HEMA-co-MMA) copolymers plotted as the emitted electrons versus binding energy (Fig. 3). The insets show the spectra of $\mathrm{C}(1 \mathrm{~s})$ and $\mathrm{O}(1 \mathrm{~s})$ that separated into sub-Gaussian curve fitted signals corresponding to the $\mathrm{C}$ and $\mathrm{O}$ bonding states. The $\mathrm{C}(1 \mathrm{~s})$ signals with binding energies between 280 and $290 \mathrm{eV}$ can be assigned to $\mathrm{C}-\mathrm{O}-\mathrm{C}, \mathrm{O}-\mathrm{C}=\mathrm{O}, \mathrm{C}-\mathrm{C}$, and $\mathrm{C}-\mathrm{H}$ groups. In the same manner, the $\mathrm{O}(1 \mathrm{~s})$ signals with binding energies around $530 \mathrm{eV}$ can be assigned to $\mathrm{C}-\mathrm{O}-\mathrm{C}$ and $\mathrm{O}-\mathrm{C}=0$ regions of the spectra.

The surface compositions of linear and hyperbranched samples varies in terms of the $\mathrm{C} \backslash 0$ ratio. It is well established that C-rich surfaces show hydrophobic, while O-rich ones yield hydrophilic behavior. ${ }^{48}$ The atomic percentages of carbon and oxygen on the surfaces of the copolymers are summarized in Table 2. The electrospray samples of all copolymers have lower $\mathrm{C} \backslash \mathrm{O}$ ratio than the drop cast samples. Notably, increased oxygen amount on their surfaces results

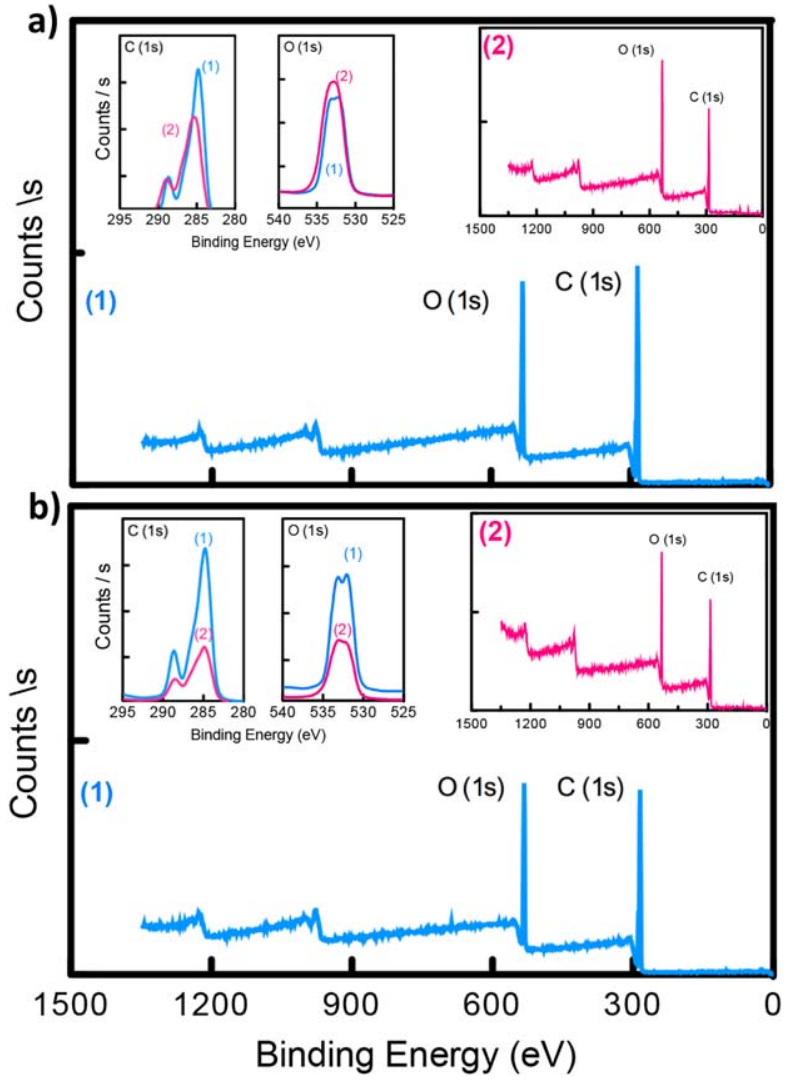

FIGURE 3 XPS spectra of (a) Lin-PH1 and (b) Hyp-PH1 copolymers. Insets show (1) drop cast and (2) electrospray samples. [Color figure can be viewed at wileyonlinelibrary.com]

an increase in the WCA value. Linear copolymers show higher $\mathrm{C} \backslash \mathrm{O}$ ratio than hyperbranched ones when the samples were prepared by drop casting. In other words, the oxygen percentage on the surface of hyperbranched ones is greater than their linear ones. Thus, the water contact angle of the drop casting hyperbranched surfaces is lower than the linear ones due to the hydrophilicity of oxygen ${ }^{48,49}$ (Fig. 1e). Drop casting is an equilibrium process so that linear chains direct the nonpolar alkyl rich groups to the surface. The lower $\mathrm{C} \backslash \mathrm{O}$ ratio in the drop casting hyperbranched surfaces is most probably due to the limited chain mobility of copolymer that carbon atom may not rise up to the surface.

TABLE 2 Surface Chemical Compositions of Linear and Hyperbranched Copolymers Calculated from $\mathrm{C}(1 \mathrm{~s})$ and $\mathrm{O}(1 \mathrm{~s})$ of XPS Spectra

\begin{tabular}{lllllllll}
\hline & \multicolumn{3}{c}{ Drop casting } & & \multicolumn{3}{c}{ Electrospray } \\
\cline { 2 - 3 } \cline { 7 - 8 } $\begin{array}{l}\text { Sample } \\
\text { name }\end{array}$ & $\mathrm{C}(1 \mathrm{~s}) \%$ & $\mathrm{O}(1 \mathrm{~s}) \%$ & $\mathrm{C} / \mathrm{O}$ & & $\mathrm{C}(1 \mathrm{~s}) \%$ & $\mathrm{O}(1 \mathrm{~s}) \%$ & $\mathrm{C} / \mathrm{O}$ \\
Lin-PH1 & 76.1 & 23.9 & 3.2 & 68.6 & 31.4 & 2.2 \\
Hyp-PH1 & 74.6 & 25.4 & 2.9 & 69.6 & 30.4 & 2.3 \\
Lin-PD2 & 73.8 & 25.1 & 2.9 & 66.3 & 32.7 & 2.1 \\
Hyp-PD1 & 72.8 & 26.4 & 2.8 & 70.1 & 29.1 & 2.4
\end{tabular}



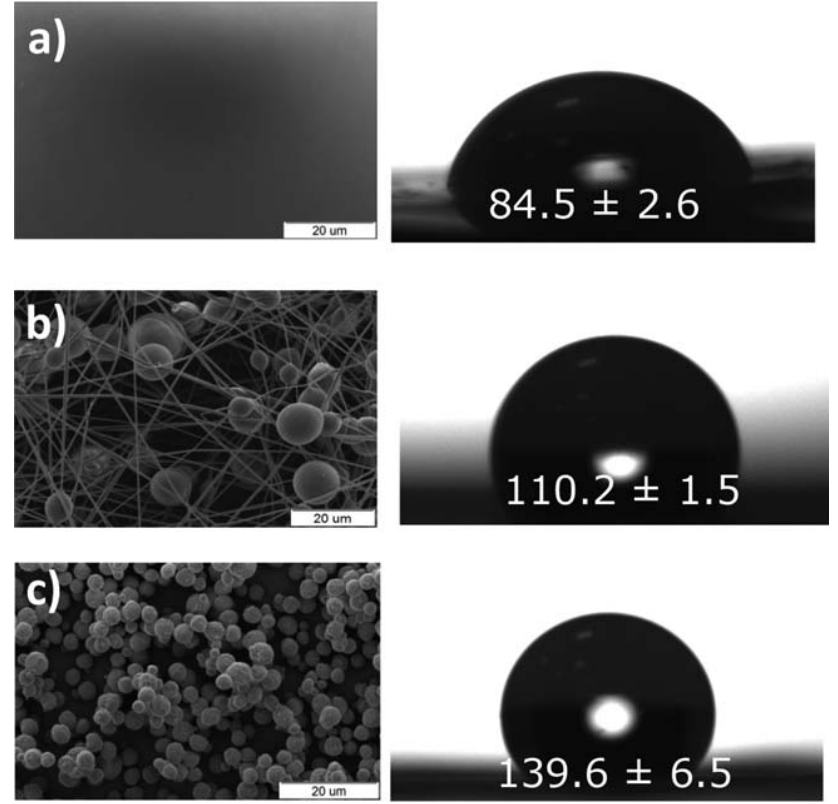

FIGURE 4 SEM micrographs and water contact angle profiles of Lin-PH2 coatings prepared by (a) drop casting, (b) $45 \mathrm{w} / \mathrm{v} \%$, and (c) $15 \mathrm{w} / \mathrm{v} \%$ electrospraying.

On the other hand, when electrospraying is applied, the $\mathrm{C} \backslash \mathrm{O}$ ratio is higher in the hyperbranched surfaces than the linear ones. Although electrosprayed hyperbranched samples are rich in terms of carbon atoms and expected to be more hydrophobic compared to linear analogs, they show less hydrophobicity compared to the coatings prepared by linear chains. Note that linear ones provide larger bead size compared to the hyperbranched ones (Fig. S2, Supporting Information). The average bead size decreases from $3.2 \pm 0.5$ to $3.0 \pm 0.6 \mu \mathrm{m}$ for the linear and hyperbranched copolymers, respectively. This result confirms the idea that surface roughness is a prerequisite for superhydrophobicity and the surface roughness of the electrospray coatings dominates the chemistry of the surfaces in wettability.

The wettability of a polymeric surface is absolutely provided by the nature of monomers. In drop casting films, WCA of DMAEMA-co-MMA is higher than the one of HEMA-co-MMA (not surprisingly) because it has more alkyl groups and high carbon atom content (Fig. 1e and Fig. S3e, Supporting Information). In such an equilibrium process, the chains have enough time and energy for directing the nonpolar alkyl groups of chains to the drop-air interface. Since air is composed of nonpolar gas molecules for instance $\mathrm{O}_{2}, \mathrm{~N}_{2}$, and $\mathrm{CO}_{2}$, it has nonpolar nature. A nonpolar-nonpolar hydrophobic interaction takes place between droplet surface and surrounding air molecules. On the other hand, the result is opposite for the coatings prepared by electrospraying. WCA of coating prepared by electrospraying of HEMA is higher than those prepared by DMAEMA. In contrast to drop casting, electrospraying is a nonequilibrium process and the structure formation rapidly occurs in the order of seconds. ${ }^{50}$ DMAEMA has bigger bulky pendant group compared to HEMA. Consequently, HEMA has higher mobility and tendency for the surface segregation of nonpolar segments, nominately alkyl groups. ${ }^{51}$
The polymer solution concentration has a significant importance on the morphology of the electrospray samples. ${ }^{52}$ The water contact angle measurements indicate that different morphologies of substrates correspond to different contact angles (Fig. 4) and it is consistent with the literature ${ }^{15,53}$ While the drop casting surface with flat surface has $85^{\circ}$ WCA and bead-onfiber sample has $110^{\circ}$, the electrospray sample with fully beads show $140^{\circ}$ WCA. The more rough surfaces with cavities show more hydrophobic behavior due to the trapping air in these cavities in accordance with Cassie-Baxter model. ${ }^{54}$ The presence of fibers obviously decreases the roughness magnitude, implicitly the WCA, and creates a nano-tailored surface while beads enhance the roughness at the micrometer level.

\section{CONCLUSIONS}

In summary, PMMA-based linear and hyperbranched copolymers with two different functional groups were synthesized using appropriate photoinitiating systems and characterized. While the use of typical cleavage type photoinitiator BAPO yielded mainly linear polymers, CQ in conjunction with inimers gave hyperbranched polymers with different branching density. These polymeric systems were subjected to drop casting or electrospray coating from DMF solution. Independent of the structure and chain architecture of the polymers, electrospray coatings exhibit hydrophobic behavior and higher WCA than the surfaces prepared by drop casting. Moreover, the coatings prepared by electrospraying of linear chains present higher WCA than their hyperbranched analogs. We show that the fluorine-free polymeric systems can also exhibit hydrophobic behavior via electrospraying. Although having comparable beady structure, HEMA was found to be more convenient comonomer for PMMA in preparation of hydrophobic polyacrylate coatings. It gives better response to electrical field due to its polar nature and linear morphology. DMAEMA, on the other hand, has larger pendant group that may prevent the chain mobility. XPS results suggest that electrical field applied during the process may favor the surface segregation of alkyl groups in linear chains that can increase the WCA of the coatings. Branching chain architecture restricts the mobility of chains and prevents the surface segregation; thus, decreases the WCA of the coating.

\section{ACKNOWLEDGMENTS}

The authors thank the Centre for Materials Research Centre of IZTECH, N. Horzum of Katip Çelebi University for WCA measurements and Istanbul Technical University Research Fund. M.C. thanks Scientific and Technological Research Council of Turkey (TUBITAK) for the financial support by means of a graduate program.

\section{REFERENCES AND NOTES}

1 R. Blossey. Nat. Mater. 2003, 2, 301-306.

2 R. Furstner, W. Barthlott, C. Neinhuis, P. Walzel. Langmuir. 2005, 21, 956-961. 
3 A. Lafuma, D. Quere. Nat. Mater. 2003, 2, 457-460.

4 K. S. Liu, L. Jiang, Annu. Rev. Mater. Res. 2012, 42, 231263.

5 X. Yao, Y. L. Song, L. Jiang. Adv. Mater. 2011, 23, 719-734.

6 X. Zhang, F. Shi, J. Niu, Y. G. Jiang, Z. Q. Wang. J. Mater. Chem. 2008, 18, 621-633.

7 D. Quere. Annu. Rev. Mater. Res. 2008, 38, 71-99.

8 W. Y. Liu, L. Y. Sun, Y. T. Luo, R. M. Wu, H. Y. Jiang, Y. Chen, G. S. Zeng, Y. J. Liu. Appl. Surf. Sci. 2013, 280, 193-200.

9 Y. Kajikawa. Mater. Chem. Phys. 2008, 112, 311-318.

10 B. J. Basu, V. Hariprakash, S. T. Aruna, R. V. Lakshmi, J. Manasa, B. S. Shruthi. J. Sol-Gel Sci. Technol. 2010, 56, 278286.

11 K. Acatay, E. Simsek, C. Ow-Yang, Y. Z. Menceloglu. Abs. Pap. Am. Chem. Soc. 2005, 229, U980-U980.

12 J. Y. Shiu, C. W. Kuo, P. L. Chen, C. Y. Mou. Chem. Mater 2004, 16, 561-564.

13 N. Bock, T. R. Dargaville, M. A. Woodruff. Prog. Polym. Sci. 2012, 37, 1510-1551.

14 M. M. Demir, I. Yilgor, E. Yilgor, B. Erman. Polymer. 2002, 43, 3303-3309.

15 J. F. Zheng, A. H. He, J. X. Li, J. A. Xu, C. C. Han. Polymer. 2006, 47, 7095-7102.

16 B. T. Song, C. Xu. Langmuir. 2016, 32, 9960-9966.

17 Y. D. Guo, D. Y. Tang, Z. L. Gong. J. Phys. Chem. C. 2012, 116, 26284-26294.

18 C. J. Hawker, J. M. J. Frechet. J. Chem. Soc., Perkin Trans. 1992, 1, 2459-2469.

19 K. L. Wooley, J. M. J. Frechet, C. J. Hawker. Polymer. 1994, 35, 4489-4495.

20 A. Sunder, R. Mulhaupt, H. Frey. Macromolecules. 2000, 33 309-314.

21 A. Sunder, R. Mulhaupt, R. Haag, H. Frey. Adv. Mater. 2000, 12, 235. +

22 K. Inoue. Prog. Polym. Sci. 2000, 25, 453-571.

23 M. Jikei, M. Kakimoto. Prog. Polym. Sci. 2001, 26, 1233-1285.

24 B. I. Voit, A. Lederer. Chem. Rev. 2009, 109, 5924-5973.

25 A. V. Ambade, A. Kumar. Prog. Polym. Sci. 2000, 25, 1141-1170.

26 S. G. Gaynor, S. Edelman, K. Matyjaszewski. Macromolecules. 1996, 29, 1079-1081.

27 Z. M. Wang, J. P. He, Y. F. Tao, L. Yang, H. J. Jiang, Y. L. Yang. Macromolecules. 2003, 36, 7446-7452.

28 C. J. Hawker, J. M. J. Frechet, R. B. Grubbs, J. Dao. J. Am. Chem. Soc. 1995, 117, 10763-10764.

29 J. Liu, W. Huang, Y. Zhou, D. Yan. Macromolecules. 2009 42, 4394-4399.
30 S. Bektas, M. Ciftci, Y. Yagci. Macromolecules. 2013, 46, 6751-6757.

31 M. Ciftci, M. U. Kahveci, Y. Yagci, X. Allonas, C. Ley, H. Tar. Chem. Commun. 2012, 48, 10252-10254.

32 M. Ciftci, S. Kork, G. Xu, M. R. Buchmeiser, Y. Yagci. Macromolecules. 2015, 48, 1658-1663.

33 M. Ciftci, P. Batat, A. L. Demirel, G. Xu, M. Buchmeiser, Y. Yagci. Macromolecules. 2013, 46, 6395-6401.

34 M. Ciftci, S. Norsic, C. Boisson, F. D'Agosto, Y. Yagci. Macromol. Chem. Phys. 2015, 216, 958-963.

35 M. Ciftci, M. Arslan, M. Buchmeiser, Y. Yagci. ACS Macro Lett. 2016, 5, 946-949.

36 M. Ciftci, M. A. Tasdelen, Y. Yagci. Polym. Int. 2016, 65, 1001-1014.

37 R. N. Wenzel. Ind. Eng. Chem. 1936, 28, 988-994.

38 A. B. D. Cassie, S. Baxter. Trans. Faraday Soc. 1944, 40, 546-551.

39 D. W. Han, A. J. Steckl. Langmuir. 2009, 25, 9454-9462.

40 H. Y. Erbil, C. E. Cansoy. Langmuir. 2009, 25, 14135-14145.

41 C. Aydogan, M. Ciftci, Y. Yagci. Macromol. Rapid Commun. 2016, 37, 650-654.

42 F. Bally, E. Ismailova, C. Brochon, C. A. Serra, G. Hadziioannou. Macromolecules. 2011, 44, 7124-7131.

43 C. A. R. Schneider, W. S. Eliceiri. K. W. Nat. Methods. 2012,

44 E. Mavroudakis, D. Cuccato, D. Moscatelli. Polymers. 2015, 7, 1789-1819.

45 F. F. Katrin, B. Kockler, C. Barner-Kowollik. Macromolecules. 2016, 49, 8572-8580.

46 J. F. Gao, W. Li, J. S. P. Wong, M. J. Hu, R. K. Y. Li. Polymer. 2014, 55, 2913-2920.

47 E. K. Kim, J. Y. Kim, S. S. Kim. J. Solid State Chem. 2013, 197, 23-28.

48 J. A. Gutierrezrodriguez, F. F. Aplan. Colloids Surf. 1984, 12, 27-51.

49 S. H. Tan, N. T. Nguyen, Y. C. Chua, T. G. Kang. Biomicrofluidics. 2010, 4,

50 M. M. Demir, B. Ozen, S. Ozcelik. Phys. Chem. B. 2009, 113, $11568-11573$.

51 L. M. Yi, X. M. Meng, X. P. Tian, W. Zhou, R. W. Chen. J. Phys. Chem. C. 2014, 118, 26671-26682.

52 R. Festag, S. D. Alexandratos, D. C. Joy, B. Wunderlich, B. Annis, K. D. Cook. J. Am. Soc. Mass Spectrom. 1998, 9, 299304.

53 X. Li, C. Wang, Y. Yang, X. F. Wang, M. F. Zhu, B. S. Hsiao. ACS Appl. Mater. Interfaces. 2014, 6, 2431-2438.

54 N. A. Patankar. J. Adhes. Sci. Technol. 2009, 23, 413-433. 